\title{
Awareness of memory functioning in patients with stroke who have a good functional outcome
}

Citation for published version (APA):

Boosman, H., van Heugten, C. M., Winkens, I., Heijnen, V. A., \& Visser-Meily, J. M. A. (2014). Awareness of memory functioning in patients with stroke who have a good functional outcome. Brain Injury, 28(7), 959-964. https://doi.org/10.3109/02699052.2014.888763

Document status and date:

Published: 01/01/2014

DOI:

10.3109/02699052.2014.888763

Document Version:

Publisher's PDF, also known as Version of record

Document license:

Taverne

Please check the document version of this publication:

- A submitted manuscript is the version of the article upon submission and before peer-review. There can be important differences between the submitted version and the official published version of record.

People interested in the research are advised to contact the author for the final version of the publication, or visit the DOI to the publisher's website.

- The final author version and the galley proof are versions of the publication after peer review.

- The final published version features the final layout of the paper including the volume, issue and page numbers.

Link to publication

\footnotetext{
General rights rights.

- You may freely distribute the URL identifying the publication in the public portal. please follow below link for the End User Agreement:

www.umlib.nl/taverne-license

Take down policy

If you believe that this document breaches copyright please contact us at:

repository@maastrichtuniversity.nl

providing details and we will investigate your claim.
}

Copyright and moral rights for the publications made accessible in the public portal are retained by the authors and/or other copyright owners and it is a condition of accessing publications that users recognise and abide by the legal requirements associated with these

- Users may download and print one copy of any publication from the public portal for the purpose of private study or research.

- You may not further distribute the material or use it for any profit-making activity or commercial gain

If the publication is distributed under the terms of Article $25 \mathrm{fa}$ of the Dutch Copyright Act, indicated by the "Taverne" license above, 


\title{
Brain Injury
}

\section{Awareness of memory functioning in patients with stroke who have a good functional outcome}

\author{
H. Boosman, C. M. van Heugten, I. Winkens, V. A. Heijnen \& J. M. A. Visser- \\ Meily
}

To cite this article: H. Boosman, C. M. van Heugten, I. Winkens, V. A. Heijnen \& J. M. A. VisserMeily (2014) Awareness of memory functioning in patients with stroke who have a good functional outcome, Brain Injury, 28:7, 959-964, DOI: 10.3109/02699052.2014.888763

To link to this article: https://doi.org/10.3109/02699052.2014.888763

曲 Published online: 21 Mar 2014.

Submit your article to this journal 줄

LII Article views: 333

Q View related articles $₫$

View Crossmark data ¿

Citing articles: 3 View citing articles $₫$ 


\title{
Awareness of memory functioning in patients with stroke who have a good functional outcome
}

\author{
H. Boosman ${ }^{1}$, C. M. van Heugten ${ }^{2,3}$, I. Winkens ${ }^{3}$, V. A. Heijnen ${ }^{4}$, \& J. M. A. Visser-Meily ${ }^{1}$ \\ ${ }^{1}$ Brain Center Rudolf Magnus and Center of Excellence for Rehabilitation Medicine, University Medical Center Utrecht and De Hoogstraat \\ Rehabilitation, Utrecht, The Netherlands, '2Department of Neuropsychology and Psychopharmacology, Faculty of Psychology and Neuroscience, \\ ${ }^{3}$ Department of Psychiatry and Neuropsychology, School for Mental Health and Neuroscience, Maastricht University, Maastricht, the Netherlands, \\ and ${ }^{4}$ De Hoogstraat Rehabilitation, Utrecht, The Netherlands
}

\begin{abstract}
Primary objective: To determine whether patients with stroke who have a good functional outcome show awareness of memory functioning and whether over- and under-estimation of memory performance are differentially related to neuropsychological performance.

Research design: Prospective cohort study.

Methods and procedures: The Barrow Neurological Institute Screen for Higher Cerebral Functions and a brief neuropsychological assessment were used to evaluate language, orientation, attention, visuospatial problem-solving, perception, reasoning, executive functioning, memory, affect and awareness of memory functioning. As for the latter, the patient's estimate of memory functioning was compared with his or her actual memory performance. Patients were divided into three groups: good-estimators (estimated performance $=$ actual performance), over-estimators (estimated performance $>$ actual performance) and underestimators (estimated performance $<$ actual performance).

Main outcomes and results: In total, 54 patients with stroke were included, of whom 27 patients were classified as good-estimators, 19 as over-estimators and eight as under-estimators. Compared to good-estimators, over-estimators had significantly lower scores for all cognitive domains. Under-estimators had significantly poorer affect compared to good-estimators.

Conclusions: These preliminary results suggest that over- and under-estimation of memory functioning can be observed in patients with stroke who have a good functional outcome and that they may reflect distinct underlying neuropsychological processes.
\end{abstract}

Keywords

Anosognosia, awareness, brain injury, cognition disorders, insight, neuropsychology

\section{History}

Received 2 September 2013

Revised 6 January 2014

Accepted 25 January 2014

Published online 28 February 2014

\section{Introduction}

Impaired awareness of deficits is a frequently observed phenomenon in patients with stroke that may lead to poor outcome [1-4]. It manifests itself as diminished insight of a specific deficit in sensory, perceptual, motor, behavioural or cognitive functioning [5]. Awareness deficits have been mostly studied in rehabilitation settings and consequently usually include patients with stroke who have considerable disabilities. However, impaired awareness of functioning may also be present in patients with stroke who have a good functional outcome (i.e. those who show no immediate significant motor, sensory or linguistic symptoms). Despite enduring cognitive and emotional impairments, these patients with 'mild' stroke are often discharged home within days and are usually not referred to a rehabilitation programme or other forms of follow-up care [6-9]. Impaired awareness in these

Correspondence: C. M. van Heugten, Maastricht University, School for Mental Health and Neuroscience, Department of Psychiatry and Neuropsychology, PO Box 616, 6200 MD Maastricht, The Netherlands. Tel: $003143 \quad 38840 \quad 91$. Fax: $003143 \quad 3884092$. E-mail: c.vanheugten@maastrichtuniversity.nl patients may lead to a failure to seek help for their cognitive and emotional impairments and consequently they may not receive the treatment that they need. All patients with stroke who have a good functional outcome should, therefore, be assessed by a neuropsychologist to screen for cognitive and emotional impairments and awareness deficits. Short screening procedures would be helpful to assess all patients with stroke. A neuropsychological screening instrument that is unique in its measurement of the patient's awareness of memory functioning and that also evaluates affect and cognitive functioning is the Barrow Neurological Institute Screen for Higher Cerebral Functions (BNIS) [10].

The BNIS awareness domain uses a performance-based discrepancy method to assess awareness of memory functioning. When using this method, the patient's opinion or estimation of his functioning is compared to an objective standard. The level of the awareness deficit is then based on the discrepancy between both measures. In the BNIS, the patient is asked to predict his memory performance in recalling words from a list. The patient's prediction is subsequently compared to the actual number of words he was able to recall [11]. The performance-based discrepancy 
method can be used to classify patients into one of the following awareness groups: good-estimators (subjective performance $=$ objective performance), over-estimators (subjective performance $>$ objective performance) and under-estimators (subjective performance $<$ objective performance) [12]. Previous studies suggested that the latter two awareness groups reflect different neuropsychological processes. Underestimating cognitive performance has, for example, been associated with depressive symptoms in patients with multiple sclerosis [13, 14]. Also, Sawchyn et al. [15] proposed an association between an under-estimation of performance and more emotional distress in patients with traumatic brain injury. Over-estimation of cognitive performance, however, has been associated with more cognitive impairments in patients with epilepsy [16] and multiple sclerosis [13].

The current study investigated whether patients with stroke who have a good functional outcome have intact awareness, over-estimation or under-estimation of memory functioning on the BNIS. Furthermore, it was examined whether over- and under-estimators differ in cognition and affect, i.e. in their performance on the other BNIS domains and on a brief neuropsychological assessment (NPA).

\section{Methods}

\section{Patients and procedure}

This study was a prospective cohort study. For this paper, secondary analyses were done. Data were used from patients from two outpatient clinics and one inpatient clinic, between August 2009 and May 2011. Patients were included if they had suffered from stroke ( $<12$ months); who had sufficient command of the Dutch language; and who had good functional outcome in terms of a Barthel Index [17] score $\geq 19$ points.

A total of 54 patients with stroke were included in this study. Of this group, $46.3 \%$ of patients had an ischaemic stroke; $11.1 \%$ a haemorrhagic stroke; and $42.6 \%$ a subarachnoid haemorrhage $(\mathrm{SAH})$. The mean time between diagnosis and assessment was 15.0 weeks $(\mathrm{SD}=12.8)$. In Table I the sample characteristics are presented.

The Barrow Neurological Institute Screen (BNIS) for higher cerebral functions [10] was administered as part of a routine procedure following stroke. All patients completed the BNIS and the brief NPA in the same session with half of all patients starting with the NPA and the other half starting with the BNIS. The study was conducted according to the Code of Conduct for Medical Research of the Council of the Dutch Federation of Medical Scientific Societies. At these clinics, all patients are informed that their files can be used anonymously for research purposes, unless they object. A review procedure by a medical ethics committee is not needed for use of anonymous routinely collected data.

\section{Materials}

\section{Barthel Index}

The Barthel Index is a measure of functional independence [17]. It contains 10 items about basic self-care and mobility (e.g. washing, transfers). Its total score has a 0-20 range. Higher scores indicate more functional independence.
Table I. Sample characteristics and comparison of characteristics for awareness sub-groups.

\begin{tabular}{|c|c|c|c|c|}
\hline & \multirow[b]{2}{*}{$\begin{array}{c}\text { Total } \\
\text { group } \\
(n=54)\end{array}$} & \multicolumn{3}{|c|}{ Sub-groups ${ }^{\mathrm{a}}$} \\
\hline & & $\begin{array}{l}\text { Good- } \\
\text { estimators } \\
(n=27)\end{array}$ & $\begin{array}{c}\text { Over- } \\
\text { estimators } \\
(n=19)\end{array}$ & $\begin{array}{l}\text { Under- } \\
\text { estimators } \\
(n=8)\end{array}$ \\
\hline Gender, female & $35.2 \%$ & $33.3 \%$ & $31.6 \%$ & $50.0 \%$ \\
\hline Median age in years & 55.0 & 50.0 & 58.0 & 56.5 \\
\hline Age range & $19-77$ & $30-77$ & $19-74$ & $46-66$ \\
\hline High education $^{\mathrm{b}}$ & $33.3 \%$ & $48.1 \%$ & $15.8 \%$ & $25.0 \%$ \\
\hline Living with partner & $83.3 \%$ & $85.2 \%$ & $84.2 \%$ & $75.0 \%$ \\
\hline \multicolumn{5}{|c|}{ Current employment status } \\
\hline Student & $1.9 \%$ & $0 \%$ & $5.3 \%$ & $0 \%$ \\
\hline Full-time/part-time & $33.4 \%$ & $37.0 \%$ & $31.6 \%$ & $25.0 \%$ \\
\hline Housemaker & $3.7 \%$ & $3.7 \%$ & $5.3 \%$ & $0 \%$ \\
\hline Sick leave & $33.4 \%$ & $33.3 \%$ & $26.4 \%$ & $50.0 \%$ \\
\hline Retired & $24.1 \%$ & $18.5 \%$ & $31.6 \%$ & $25.0 \%$ \\
\hline Unknown & $3.7 \%$ & $7.4 \%$ & $0 \%$ & $0 \%$ \\
\hline \multicolumn{5}{|l|}{ Handedness } \\
\hline Left & $11.1 \%$ & $7.2 \%$ & $15.8 \%$ & $12.5 \%$ \\
\hline Right & $88.9 \%$ & $92.6 \%$ & $84.2 \%$ & $87.5 \%$ \\
\hline \multicolumn{5}{|l|}{ Type of stroke } \\
\hline Infarction & $46.3 \%$ & $44.4 \%$ & $47.4 \%$ & $50.0 \%$ \\
\hline Haemorrhagic & $11.1 \%$ & $11.1 \%$ & $10.5 \%$ & $12.5 \%$ \\
\hline $\begin{array}{l}\text { Subarachnoid } \\
\text { haemorrhage }\end{array}$ & $42.6 \%$ & $44.4 \%$ & $42.1 \%$ & $37.5 \%$ \\
\hline \multicolumn{5}{|l|}{ Location of stroke $\mathrm{c}^{\mathrm{c}}$} \\
\hline Left hemisphere & $45.2 \%$ & $46.7 \%$ & $54.5 \%$ & $20.0 \%$ \\
\hline Right hemisphere & $41.9 \%$ & $46.7 \%$ & $27.3 \%$ & $60.0 \%$ \\
\hline $\begin{array}{l}\text { Left and right } \\
\text { hemisphere }\end{array}$ & $9.7 \%$ & $6.7 \%$ & $9.1 \%$ & $20.0 \%$ \\
\hline Unknown & $3.2 \%$ & $0 \%$ & $9.1 \%$ & $0 \%$ \\
\hline $\begin{array}{l}\text { Median time } \\
\text { post-stroke (weeks) }^{\mathrm{d}}\end{array}$ & 10.0 & 9.0 & 12.5 & 7.0 \\
\hline \multicolumn{5}{|c|}{$\begin{array}{l}{ }^{\mathrm{a}} \text { Good-estimators } \quad \text { (estimated performance }=\text { actual performance); } \\
\text { over-estimators (estimated performance }>\text { actual performance); } \\
\text { under-estimators (estimated performance }<\text { actual performance). } \\
{ }^{\mathrm{b}} \text { High education } \geq \text { finished high school; Low education }<\text { finished high } \\
\text { school. } \\
{ }^{\mathrm{c}} \text { Only for infarction and haemorrhagic stroke. } \\
{ }^{\mathrm{d}} n=52 \text { (one missing value in the good-estimator and over-estimator } \\
\text { sub-group). }\end{array}$} \\
\hline
\end{tabular}

In accordance with other studies, this study used $\geq 19$ points as a cut-off value for functional independence $[18,19]$.

\section{Barrow Neurological Institute Screen for Higher Cerebral Functions (BNIS)}

The BNIS [10] is a cognitive screening instrument that includes a pre-screening and a screening phase. The prescreening is based on three domains: arousal-alertness, basic language abilities and co-operation, which are scored on a 3 -point rating scale. The pre-screening is based on observations by the experimenter. For each of the three items patients have to attain a score of at least 2 in order to proceed to the screening phase. These three pre-screening items contribute to the BNIS total score. The BNIS screening part contains 27 items in seven domains: language, orientation, attention and concentration, visuospatial problem-solving, memory, awareness and affect. The awareness domain is based on evaluation by the patient. The patient is read three words and asked to repeat them. Subsequently, the patient is asked to estimate how many words he or she will recall after $\sim 5-10$ minutes: $0,1,2$ or all 3 . The patient's estimation is compared 
to the actual number of recalled words. The other BNIS domains on cognition and affect are described in detail elsewhere [8, 10].

Items are summed to obtain domain scores and a total BNIS score. The total BNIS score has a 0-50 range. Higher scores indicate better functioning. Interpretation of impaired cognitive performance is based on a cut-off value of $<47$ for patients $\leq 55$ years and $<43$ for patients $>55$ years [10]. Previous studies have reported good psychometric properties for the BNIS in patients with brain injury [8, 10, 20-26]. The BNIS takes 10-15 minutes to administer [10].

\section{Neuropsychological assessment (NPA)}

The brief NPA consisted of a core battery that was administered to all patients. Since the cognitive screening was part of standard care, additional neuropsychological tests varied depending on, for instance, cognitive complaints reported by the patient. The core battery consisted of six conventional neuropsychological tests. The Star Cancellation Test (SCT) [27] was used to assess perception. Language performance was assessed with the Boston Naming Test (BNT) [28] short form. The Rey Auditory Verbal Learning Test (RAVLT) [29] was used to assess verbal memory. The Trail Making Test Part A (TMT-A) [30] was used to evaluate attention. Abstract reasoning was determined with Raven's Advanced Progressive Matrices (RAPM) [31] short form. To assess executive functioning, the Stroop Colour and Word Test [32] was used. For the current study the variable of interest was the Stroop interference score which was calculated with the following formula: (card $3-(($ card $1+$ card 2$) / 2)$ ). The neuropsychological tests are described in more detail elsewhere [33].

\section{Statistical analysis}

The BNIS awareness score was used to divide the patients into three sub-groups: good-estimators (estimated number of recalled words = number of words actually recalled); overestimators (estimated number of recalled words $>$ number of words actually recalled) and under-estimators (estimated number of recalled words $<$ number of words actually recalled). Descriptive statistics were used to describe characteristics of the total stroke population and the sub-groups. Non-parametric statistics (Chi-square tests, Mann Whitney $U$-tests, Kruskall-Wallis tests, Fisher's exact tests) were used to compare the sub-groups regarding demographic (gender, age, education) and injury (type of stroke, stroke location, time post-stroke) characteristics. The differences between the sub-groups regarding BNIS domain scores and NPA scores were investigated by means of Kruskall-Wallis tests and Mann-Whitney $U$-tests. Data were analysed using SPSS version 21.0. Alpha was set at 0.05 .

\section{Results}

\section{Patients}

A total of 54 patients with stroke who had a good functional outcome were included. All patients passed the BNIS prescreening. Based on their BNIS awareness score, 27 patients were classified as good-estimators. An equally large group of
Table II. Difference between estimated performance and actual performance.

\begin{tabular}{lcc}
\hline & $\begin{array}{c}\text { Difference score } \\
\text { Awareness group }\end{array}$ & \\
\hline Under-estimators $(n=8)$ & -3 & $\%(n)$ \\
\hline Good-estimators $(n=27)$ & -2 & $0 \%$ \\
& -1 & $3.7 \%(2)$ \\
Over-estimators $(n=19)$ & 0 & $11.1 \%(6)$ \\
& 1 & $50.0 \%(27)$ \\
& 2 & $18.5 \%(10)$ \\
\hline
\end{tabular}

${ }^{\mathrm{a}}$ Good-estimators (estimated performance $=$ actual performance); over-estimators (estimated performance $>$ actual performance); underestimators (estimated performance $<$ actual performance).

patients showed awareness deficits: 19 patients were classified as over-estimators and eight patients were underestimators. In Table II, the difference between the estimated number of recalled words and the number of words actually recalled is shown for the three groups.

The sub-groups were compared regarding their demographic and injury characteristics. There were no significant differences between the three sub-groups regarding age $\left(\chi^{2}=3.185, p=0.203\right)$ and gender (under- vs. over-estimators $p=0.415$; under- vs. good-estimators $p=0.433$; over- vs. good-estimators $\left.\chi^{2}=0.016, p=0.901\right)$. There was a significant difference in education (under- vs. over-estimators $p=0.616$; under- vs. good-estimators $p=0.419$; over- vs. good-estimators $\left.\chi^{2}=5.148, p=0.023\right)$. There were significantly more high educated patients in the good-estimator group $(48.1 \%)$ than in the over-estimator group $(15.8 \%)$. Regarding injury characteristics, no significant betweengroup differences were found regarding time post-stroke $\left(\chi^{2}=3.540, p=0.170\right)$; type of stroke (infarction or subarachnoid haemorrhage) (under- vs. over-estimators $p=1.00$; under- vs. good-estimators $p=1.00$; over- vs. good-estimators $\chi^{2}=0.034, p=0.853$ ); stroke location (left or right) (undervs. over-estimators $p=0.335$; under- vs. good-estimators $p=0.649$; over- vs. good-estimators $p=0.702$ ).

\section{Awareness and neuropsychological performance}

Scores on the BNIS and NPA for the three groups are displayed in Table III. There were significant between-group differences for all BNIS domains, the BNIS total score and all cognitive tests of the NPA except for RAVLT delayed recognition $\left(\chi^{2}=2.709, p=0.258\right)$. In total, $44.4 \%$ of goodestimators, $75.0 \%$ of under-estimators and $89.5 \%$ of overestimators scored below the BNIS cut-off for impairment on the BNIS total score ( $<47$ for patients $\leq 55$ years; $<43$ for patients $>55$ years [10]). Compared to good-estimators, overestimators had significantly poorer performance for the BNIS domains orientation ( $\mathrm{U}=116.0, z=-4.09, p=0.000)$; attention $(U=120.0, z=-3.21, p=0.001)$; visuospatial problemsolving $\quad(U=128.5, \quad z=-2.99, \quad p=0.003)$; memory $(U=36.5, \quad z=-4.99, \quad p=0.000)$; the BNIS total score $(U=40.5, z=-4.84, p=0.000)$; the Stroop Colour and Word Test $(U=104.0, \quad z=-3.22, \quad p=0.001)$; TMT-A $(U=103.5, \quad z=-3.42, \quad p=0.001) ;$ Boston Naming Test $(U=120.0, \quad z=3.05, \quad p=0.002) ; \quad$ RAPM $\quad(U=88.0$, 
Table III. Awareness groups and neuropsychological performance.

\begin{tabular}{|c|c|c|c|c|c|c|c|c|c|c|c|c|c|}
\hline & \multirow[b]{2}{*}{ Score range } & \multicolumn{3}{|c|}{$\begin{array}{c}\text { (1) Good-estimators } \\
(n=27)\end{array}$} & \multicolumn{3}{|c|}{$\begin{array}{c}\text { (2) Over-estimators } \\
(n=19)\end{array}$} & \multicolumn{3}{|c|}{$\begin{array}{l}\text { (3) Under-estimators } \\
(n=8)\end{array}$} & \multicolumn{3}{|c|}{ Group comparison } \\
\hline & & Median & Range & IQR & Median & Range & IQR & Median & Range & IQR & $1,2,3 p^{\mathrm{a}}$ & $1,2 p^{\mathrm{b}}$ & $1,3 p^{\mathrm{b}}$ \\
\hline BNIS orientation & $0-3$ & 3.0 & $2-3$ & 0 & 2.0 & $1-3$ & 1.0 & 3.0 & $2-3$ & 0 & $0.000 *$ & $0.000^{*}$ & 0.353 \\
\hline BNIS attention & $0-3$ & 2.0 & $1-3$ & 1.0 & 1.0 & $0-3$ & 1.0 & 2.0 & $1-3$ & 1.5 & $0.005^{*}$ & $0.001 *$ & 0.247 \\
\hline BNIS visuospatial & $0-8$ & 7.0 & $5-8$ & 2.0 & 6.0 & $3-7$ & 2.0 & 7.0 & $3-8$ & 1.0 & $0.012 *$ & $0.003 *$ & 0.635 \\
\hline \multicolumn{14}{|l|}{ RAVLT } \\
\hline Immediate recall & $0-75$ & 41.0 & $27-70$ & 14.0 & 30.0 & $17-52$ & 18.0 & 36.5 & $30-57$ & 14.3 & $0.016^{*}$ & $0.006^{*}$ & 0.387 \\
\hline Delayed recall & $0-15$ & 9.0 & $2-14$ & 5.0 & 5.0 & $0-13$ & 4.0 & 6.5 & $1-11$ & 5.8 & $0.009 *$ & $0.002 *$ & 0.221 \\
\hline Delayed recognition & $0-30$ & 29.0 & $11-30$ & 5.0 & 28.0 & $11-30$ & 7.0 & 29.0 & $24-30$ & 5.3 & 0.258 & - & - \\
\hline Stroop ${ }^{\mathrm{d}, \mathrm{e}}$ & RT & 38.5 & $13-98$ & 28.0 & 66.3 & $38-183$ & 58.6 & 42.5 & $31-96$ & 16.1 & $0.004 *$ & $0.001 *$ & 0.582 \\
\hline Trail Making Test $-\mathrm{A}^{\mathrm{e}}$ & RT & 31.0 & $20-56$ & 13.0 & 61.0 & $22-251$ & 56.0 & 35.0 & $20-61$ & 21.3 & $0.002 *$ & $0.001 *$ & 0.542 \\
\hline
\end{tabular}

IQR, interquartile range; RAVLT, Rey Auditory Verbal Learning Test; RAPM, Raven's Advanced Progressive Matrices; Stroop, Stroop Colour and Word Test.

${ }^{a}$ Kruskall-Wallis test.

${ }^{\mathrm{b}}$ Mann-Whitney $U$-test.

${ }^{\mathrm{c}}$ The pre-screening has a $0-9$ range.

${ }^{\mathrm{d}}$ One patient in the over-estimator group did not complete this test due to reading problems.

${ }^{\mathrm{e}}$ Higher score reflects worse performance. *Significant at the 0.05 level (two-tailed).

$z=-3.80, \quad p=0.000) ; \quad$ RAVLT immediate $(U=132.5$, $z=-2.77, p=0.006)$ and delayed $(U=120.5, z=-3.05$, $p=0.002)$ recall; and Star Cancellation Test $(U=172.5$, $z=-2.31, p=0.021)$. Under-estimators had significantly lower scores for the BNIS affect domain compared to goodestimators $(U=46.5, z=-2.75, p=0.006)$. The underestimators did not significantly differ from the good estimators on any of the cognitive tests.

\section{Discussion}

The results of this exploratory study suggest that impaired awareness of memory functioning is not limited to patients with stroke who have considerable disabilities, but can also be observed in patients with stroke who have a good functional outcome. Half of the patients in this study over-estimated or under-estimated their memory functioning. The results further show that, compared to good-estimators, over-estimators had poorer cognitive functioning and under-estimators had poorer affect.

These findings suggest that over-estimation and underestimation of memory functioning are related to different neuropsychological mechanisms. These findings are in line with previous studies and with cognitive theories of awareness. Giovagnoli [16] and Carone et al. [13], for example, suggested that impaired awareness is a specific cognitive impairment directly resulting from brain damage and they already reported an association between over-estimation of cognitive performance and cognitive impairments in patients with brain injury $[13,16]$.

Under-estimation, however, may be related to psychological or emotional functioning. Patients who underestimated their memory performance had poorer affect than good-estimators. The vast majority of under-estimators did not obtain full credit for the affect domain. These results suggest that an under-estimation of performance is associated with an emotional component. This is supported by previous studies in which emotional factors such as depression and emotional distress were related to an under-estimation of cognitive performance [13-15].

If different mechanisms underlie over-estimation and under-estimation of functioning, then, in clinical practice it is important to distinguish between patients who overestimate and patients who under-estimate their cognitive performance. These two groups may need other interventions. Patients with stroke who over-estimate their memory performance may, for example, engage in activities that they are not capable of performing. These patients may benefit from psycho-education concerning their deficits and from interventions aimed at increasing awareness such as feedback interventions [34]. In contrast, patients who under-estimate their memory performance may needlessly avoid activities that they are perfectly capable of doing. These patients may need some kind of cognitive behaviour therapy first to decrease their fears and anxiety [35].

Some limitations of this study should be noted. First, it included a small, convenience sample of patients with heterogeneous diagnoses. In particular, the under-estimator group had a small sample size. Second, it is possible that good-estimators, under-estimators and over-estimators differed in the type, location and volume of stroke lesions. Previous studies suggested a strong association between impaired awareness and right-hemisphere lesions that involve cortical (insular, temporal and parietal lobes) and subcortical structures (thalamus, basal ganglia) [4]. Although this study did not find significant between-group differences regarding stroke location (left, right), it is possible that, in this study, the good-estimators more often had lacunar, less strategic or 
smaller volume lesions than the under- or over-estimators and, consequently, better neuropsychological performance. Since further topography of the strokes was not available, the authors were not able to control for these factors. Second, the over-estimators were lower educated than the goodestimators. However, solely including high educated patients $(n=18)$ or solely including low educated patients $(n=36)$ yielded similar results. Low-educated over-estimators had significantly lower cognitive performance compared to goodestimators. High educated over-estimators had significantly lower cognitive performance compared to high educated good-estimators and high educated under-estimators had significantly poorer affect than high educated good-estimators. A third limitation is that no other emotional assessments other than the BNIS affect domain were used to confirm that under-estimating is associated with some kind of emotional problems. Last, the differentiation between good-estimators, over-estimators, and under-estimators was based on a single awareness score with a small score range (0-3). In $59 \%$ of incorrect estimations, estimated and actual performance differed by only 1 point. Also, the small score range may have caused a ceiling effect and, thus, a possible lack of sensitivity for more subtle awareness problems. Furthermore, mis-estimations of memory functioning are also found in healthy persons and, therefore, do not necessarily imply impaired awareness $[10,36]$. With respect to the BNIS, 35\% of healthy persons mis-estimated their memory functioning in previous studies [10]. Hence, an over- or under-estimation of performance needs confirmation by a comprehensive neuropsychological assessment to diagnose impaired awareness. Further research is needed to evaluate the sensitivity of the BNIS awareness domain for detecting awareness problems and to determine whether these findings are specific to patients with stroke or that similar associations are present in healthy controls as well.

In conclusion, the preliminary results of this study suggest that impaired awareness of memory functioning can be observed in patients with stroke who have a good functional outcome. Results further seem to suggest that under- and over-estimation of memory performance reflect different neuropsychological processes. Further studies with larger samples and other measures are needed to confirm these results and to determine whether patients with poor memory awareness are also impaired on the more general domain of awareness.

\section{Declaration of interest}

This project is part of the research programme Cognitive Rehabilitation which is funded by the National Initiative on Brain and Cognition in the Netherlands (NWO number 056-11-014). The authors report no conflicts of interest.

\section{References}

1. Hartman-Maeir A, Soroker N, Ring H, Katz N. Awareness of deficits in stroke rehabilitation. Journal or Rehabilitation Medicine 2002;34:158-164.

2. Hartman-Maeir A, Soroker N, Oman SD, Katz N. Awareness of disabilities in stroke rehabilitation - a clinical trial. Disability and Rehabilitation 2003;25:35-44.
3. Jehkonen M, Laihosalo M, Kettunen J. Anosognosia after stroke: Assessment, occurrence, subtypes and impact on functional outcome reviewed. Acta Neurologica Scandinavica 2006;114: 293-306.

4. Starkstein SE, Jorge RE, Robinson RG. The frequency, clinical correlates, and mechanism of anosognosia after stroke. The Canadian Journal of Psychiatry 2010;55:355-361.

5. Orfei MD, Caltagirone C, Spalletta G. The evaluation of anosognosia in stroke patients. Cerebrovascular Diseases 2009;27: 280-289.

6. Planton M, Peiffer S, Albucher JF, Barbeau EJ, Tardy J, Pastor J, Januel AC, Bezy C, Lemesle B, Puel M, et al. Neuropsychological outcome after a first symptomatic ischaemic stroke with 'good recovery'. European Journal of Neurology 2012;19:212-219.

7. Schweizer TA, Al-Khindi T, Macdonald RL. Mini-Mental State Examination versus Montreal Cognitive Assessment: Rapid assessment tools for cognitive and functional outcome after aneurysmal subarachnoid hemorrhage. Journal of the Neurological Sciences 2012;316:137-140.

8. Boosman H, Visser-Meily JMA, Post MWM, Duits A, van Heugten $\mathrm{CM}$. Validity of the barrow neurological institute (BNI) screen for higher cerebral functions in stroke patients with good functional outcome. The Clinical Neuropsychologist 2013;27:667-680.

9. Wolf TJ, Rognstad MC. Changes in cognition following mild stroke. Neuropsychological Rehabilitation 2013;23:256-266.

10. Prigatano GP, Amin K, Rosenstein LD. Administration and scoring manual for the BNI screen for higher cerebral functions. Phoenix, AZ: Barrow Neurological Institute; 1995.

11. Galeone F, Pappalardo S, Chieffi S, Iavarone A, Carlomagno S. Anosognosia for memory deficit in amnestic mild cognitive impairment and Alzheimer's disease. International Journal of Geriatric Psychiatry 2010;26:695-701.

12. Hoofien D, Gilboa A, Vakil E, Barak O. Unawareness of cognitive deficits and daily functioning among persons with traumatic brain injuries. Journal of Clinical and Experimental Neuropsychology 2004;26:278-290.

13. Carone DA, Benedict RH, Munschauer FE, Fishman I, WeinstockGuttman B. Interpreting patient/informant discrepancies of reported cognitive symptoms in MS. Journal of the International Neuropsychological Society 2005;11:574-583.

14. Julian L, Merluzzi NM, Mohr DC. The relationship among depression, subjective cognitive impairment, and neuropsychological performance in multiple sclerosis. Multiple Sclerosis 2007; 13:81-86.

15. Sawchyn JM, Mateer CA, Suffield JB. Awareness, emotional adjustment, and injury severity in postacute brain injury. Journal of Head Trauma Rehabilitation 2005;20:301-314.

16. Giovagnoli AR. Awareness, overestimation, and underestimation of cognitive functions in epilepsy. Epilepsy \& Behavior 2013;26: 75-80.

17. Wade DT, Collin C. The Barthel ADL Index: A standard measure of physical disability? International Disability Studies 1988;10: 64-67.

18. Hankey GJ, Langhorne P. Services for reducing the duration of hospital care for acute stroke patients. Stroke 2006;37:276-277.

19. Schiemanck SK, Kwakkel G, Post WMM, Kappelle LJ, Prevo AJH. Predicting long-term independency in activities of daily living after middle cerebral artery stroke. Stroke 2006;37:1050-1054.

20. Denvall V, Elmståhl S, Prigatano GP. Replication and construct validation of the barrow neurological institute screen for higher cerebral function with a Swedish population. Journal of Rehabilitation Medicine 2002;34:153-157.

21. Lai FDM, Prigatano GP. Wechsler IQ, Hong Kong list learning test, and the BNI screen for higher cerebral functions. Barrow Quarterly 2004;20:16-18.

22. Prigatano GP. BNI Screen for Higher Cerebral Functions: Rationale and initial validation. Barrow Quarterly 1991;7:2-9.

23. Prigatano GP, Amin K, Rosenstein LD. Validity studies on the BNI Screen for higher cerebral functions. Barrow Quarterly 1992;9:2-9.

24. Prigatano GP, Palencia B. Halstead Impairment index, Wechsler IQ, and the BNI screen for higher cerebral functions. Barrow Quarterly 2000;16:22-27.

25. Hofgren C, Esbjörnsson E, Aniansson H, Sunnerhagen KS. Application and validation of the barrow neurological institute for higher cerebral functions in a control population and in patient 
groups commonly seen in neuro-rehabilitation. Journal of Rehabilitation Medicine 2007;39:547-553.

26. Prigatano GP. An analysis of the construct-related and ecological validity of the BNI screen for higher cerebral functions by Peter J. Wass: A synopsis. Barrow Quarterly 2004;20:4-6.

27. Wilson B, Cockburn J, Halligan PW. Behavioural Inattention Test. Bury St. Edmunds: Pearson Education; 1987.

28. Kaplan EF, Goodglass H, Weintraub S. The Boston Naming Test. Philadelphia, PA: Lea \& Febiger; 1978.

29. Rey A. L'examen clinique en psychologie. Paris: Presse Universitaire de France; 1958.

30. Reitan R. Trail Making test: Manual for administration, scoring, and interpretation. Bloomington, IN: Indiana University; 1956.

31. Raven J. Occupational user's guide: Raven's advanced progressive matrices \& mill hill vocabulary scale. Oxford: Oxford Psychologists Press; 1994.
32. Stroop J. Studies of interference in serial verbal reaction. Journal of Experimental Psychology 1935;18:643-662.

33. Lezak MD, Howieson DB, Loring DW. Neuropsychological assessment. 4th ed. New York: Oxford University Press; 2004.

34. Schmidt J, Lannin N, Fleming J, Ownsworth T. Feedback interventions for impaired self awareness following brain injury: A systematic review. Journal of Rehabilitation Medicine 2011;43: $673-680$

35. Waldron B, Casserly LM, O'Sullivan C. Cognitive behavioural therapy for depression and anxiety in adults with acquired brain injury. What works for whom? Neuropsychological Rehabilitation 2013;23:64-101.

36. Schoo LA, van Zandvoort MJE, Biessels GJ, Kappelle LJ, Postma A. Insight in cognition: Self-awareness of performance across cognitive domains. Applied Neuropsychology: Adult 2013; 20:95-102. 